\section{Tempos e ventos da educação comparada}

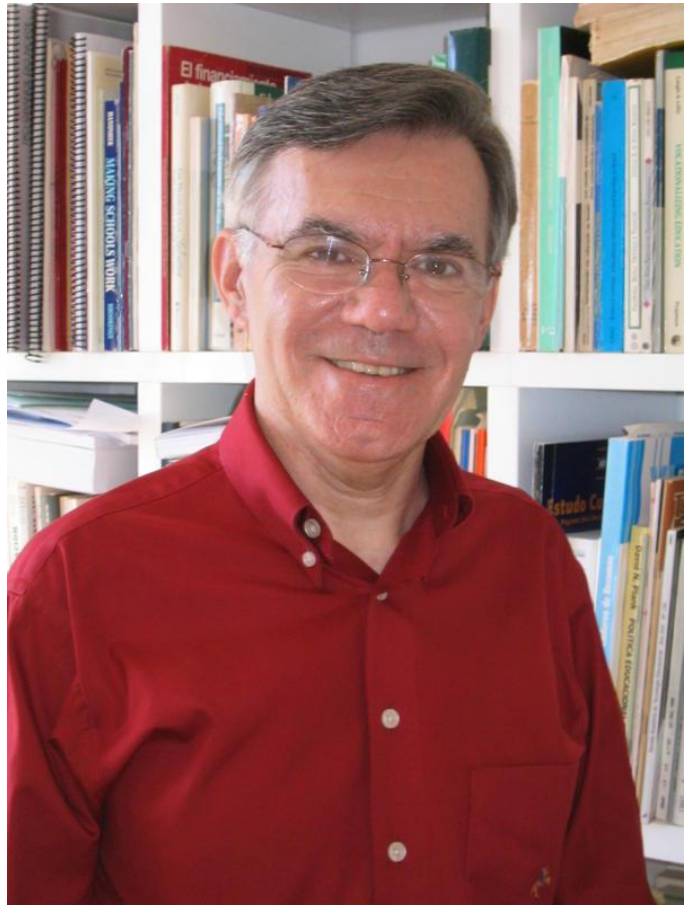

Candido Alberto Gomes ${ }^{1}$

Na América Latina, econômica e culturalmente introvertida, a educação comparada nos anos 1980 era como uma janela aberta. Vários Estados não eram democráticos de Direito, o que a tornou até certo ponto arriscada, conforme teorias e metodologias. A chamada

1 Ex-presidente da SBEC, ex-membro e presidente do Comitê de Pesquisa do Conselho Mundial das Sociedades de Educação Comparada-candidoacg@gmail.com década perdida do Continente, resultado da sua extroversão financeira, decorreu implacavelmente, inclusive com as moratórias do México e do Brasil. Thatcher já era primeira-ministra do Reino Unido. Reagan foi eleito presidente dos Estados Unidos. Logo o verbo solto de Jane Fonda se fez ouvir numa cadeia de rádio: Reagan was a lousy actor and will be a lousy president. Com efeito, foram desmontados programas sociais, seguindo a agenda de sempre: corte dos apoios aos pobres e desempregados (suspeitos de serem perdedores por não serem produtivos), menor interesse nos direitos humanos, fim progressivo das políticas afirmativas, desprezo à ecologia e desinteresse pelas minorias. Os tempos da competitividade e da eficiência substituíam o Estado de bemestar, como se realmente lhe faltasse dinheiro. Fazia-se vista grossa à financeirização dos Estados, entre outros fatores, 
que tragavam os seus recursos. Avaliados por agências de notação e outras entidades, logo se tornariam devedores mais e menos valiosos ou até "lixo". Hoje os países dependem tanto destas agências localizadas em países centrais como as antigas colônias europeias, na própria América Latina e outros continentes, quanto em relação às respectivas metrópoles. $\mathrm{O}$ Brasil e outros países haviam mergulhado sua cabeça na areia e prosseguiam na industrialização substitutiva de importações, cujo modelo se esgotara, segundo reiteradas advertências. A "nova economia" (não assim tão nova) demorava certo tempo a chegar à periferia, mas chegava.

Depois de alguns anos acabou a guerra fria: não mais era preciso se preocupar com a sociedade ou persuadir que o capitalismo era um sistema econômico justo. $\mathrm{O}$ foco passou a ser o dinheiro, uma bola de neve em rede, como só houvesse a mão invisível dos mercados. As próprias leis e normas eram e são constantemente testadas além dos seus limites, de modo a desafiar e, se possível, esgotar os recursos dos Estados e sua Justiça. Afinal, a mão invisível levaria a palma sobre a visível. Depois do Muro de Berlim, o bloco socialista na Europa Central e Oriental caiu quase por si mesmo, com revoluções de veludo. Viagens prévias antecipavam um mundo que escapava entre os dedos. Alguns anos antes, uma visita a Budapeste desvelou o conflito entre jovens e beneficiários da ordem estabelecida. Os primeiros enchiam as missas em São Matias e cantavam hinos a plenos pulmões. Os membros das academias pontificavam, mas a jovem oposição já lhes causava arranhões. Em outra capital, o formidável metrô (exemplo de transporte para o povo) proporcionava uma visão das desigualdades sociais àqueles que ousavam 
escapar ao quadrilátero vigiado dos turistas. Ao emergir de diferentes estações, deparava-se, no comércio e nas casas, com paisagens sociais diversas. Vieram, em seguida, as liberdades individuais para estes países. A abertura da educação comparada era ansiada pelos colegas educadores. Queriam ver o mundo sem óculos coloridos. Estavam ávidos de portas e janelas abertas, para conhecer o mundo. Queriam aprender inglês e francês, não russo e não necessariamente alemão. Estas liberdades individuais, entretanto, foram acompanhadas por uma chuva de estrelas cadentes, o declínio dos direitos sociais e econômicos.

Com a queda do Muro, passou-se cada vez mais a tratar de performatividade, processos competitivos entre instituições educativas; avaliações quantitativas internas e externas, com frequência transformadas em fetiches; criação de quase- mercados, na expectativa de que a competição eliminasse os mais fracos pelo triunfo dos mais fortes. Como os séculos XIX e XX mostraram, não importa a empiria: as ideologias são mais sedutoras que a razão, atraem intelectuais e massas, tornamse matéria de crença e se sustentam em fortes interesses. Em outras palavras, instala-se a cegueira narrada por Saramago. Estava, assim, inventada a pedra filosofal, que em tudo busca fazer dinheiro, transformando pessoas e coisas em mercadorias para consumo ou oportunidades de negócio. Assim, ampliava-se a senda da concentração de renda. Como um fenômeno social total, desenharam-se os cenários para tocar a educação com a referida pedra (os alquimistas da Idade Média não sabiam talvez que era um símbolo e não supunham que $\mathrm{o}$ seu achamento levasse séculos). Ricas tecnologias vendidas pelos países desenvolvidos, 
educação a distância de baixa qualidade, auto estudo, aulas "presenciais" por meio de projeções, educação em rede, redução do custo/aluno, aumento do lucro, tudo isso começou em parte velado, com uma certa vergonha da coisificação. Depois, se tornou ampla e desvergonhada, colonizando os "mercados" dos países em desenvolvimento, para lhes prestar serviços no limite estrito do que podiam pagar e passando por cima da legislação e normas.

Estas observações não significam que, como na Revolução Industrial inglesa, se deva destruir as máquinas. Nem representa uma acendrada devoção a leis e regras arcaicas, definidas muitas vezes com vieses em favor de certos grupos oligopolísticos. A sociologia do direito explica. Transformados professores e estudantes em pessoas inanimadas a quem se compram e vendem serviços por preços de liquidação, a educação superior foi vítima preferencial, ao transformar universidades em fábricas de pesquisas (não raro com financiamento onde se embutem as expectativas dos resultados) e em supermercados do ensino. A filosofia da educação cedeu lugar a um processo envolvente, em que supostamente tudo se compra e tudo se vende. A inspiração passou a habitar um campo de refugiados. Não como emigrante ou imigrante, porém uma migrante, que mal sabe de onde partiu e se encontra quase sempre em trânsito, como as multidões que hoje fogem das guerras e da fome, inclusive de justiça.

A acumulação de lucros contrasta com a desvalorização dos diplomas, a chamada inflação educacional, de tal modo que os alunos se empenham e se endividam para obterem rendimentos decrescentes da educação em que imaginam investir. Estes são alguns traços captados, 
com coração e mente. Não é de agora, mas a brecha civilizacional se dilata em abismo: abundância de knowhow e carência de know-what e know-why. É preciso sacar o quanto antes todos os recursos, inclusive os da Terra, e pesquisar outro planeta para os have's viverem e colonizarem. Assim, se distanciarão dos fracassados have not's. Os primeiros triunfaram porque, seguindo as leis do mercado, foram "legítimos" ganhadores. Mas as leis do mercado são absolutas? Não projetariam os interesses de determinados grupos, como as leis representavam, muito antes de Maquiavel?

Como me solicitaram esta entrevista, suponho, ao menos no meu caso, que já tenha decaído ao status de dinossauro. Por isso, tomo a liberdade de fazer um brevíssimo retrospecto do Brasil destas cinco últimas décadas e de como a educação comparada passou pelas contradições do seu contexto.

O fato colonial é básico, nós sabemos, bem como a educação ornamental e beletrista que aqui se estabeleceu. Até Capistrano de Abreu historiou isto. Uma das nossas contradições, já como país relativamente independente, herdada da metrópole, foi a do ufanismo versus pessimismo. Ora exaltávamos as riquezas do Brasil e o seu glorioso futuro (algo como a volta de D. Sebastião), ora afundávamos no pessimismo, com frequência a comparar-nos com países industrializados, supostamente justos, democratas, ordeiros de uma suposta ordem, mais imaginada que real. De fato, o deputado do Império Rui Barbosa, encarregado de relatar uma reforma educacional, solicitou aos seus pares tempo para importar livros, poliglota que era, e poder oferecer-lhes o melhor. $\mathrm{O}$ relator não caiu na tolice 
copiativa colonial nem na xenofobia. Preparou Pareceres que merecem ser lidos hoje para constatar a atualidade dos problemas educacionais brasileiros. Obscurantista foi o Parlamento, que sequer os ofereceu à leitura e tratou de engavetá-los. Considerados irrelevantes, deixaram de ser perigosos. Teria o Brasil mudado tanto de lá para cá? A educação seria coisa séria ou um ornamento? Ainda estaríamos à espera inútil de um salvador como D. Sebastião, de armadura, num navio feericamente iluminado? Ou como o trágico Frei Luís de Sousa, chocado com as mudanças na sua família e com a decadência de Portugal?

Se dinossauro, uso a licença da emoção. Só durante um tempo fui esponja da pedagogia bancária, monologal, prestando conta, nos exames, dos conteúdos injetados. Até comecei assim no magistério, era o modelo vigente, mas depois mudei. Por isso, me permito as considerações deste texto.

Com a razão delineio aqui um desenho em breves rabiscos. Durante longo período o nacionalismo se entretecia à visão promissora da pátria, um futuro grandioso (sempre futuro), que se conhece como ufanismo. É significativo que, quando ocorreu a Revolução de 1930 no Rio de Janeiro, encontrava-se, num navio fundeado na baía de Guanabara, um grande comparatista português. Num périplo pela América Latina, havia sido convidado pelos escolanovistas a proferir conferências. Naquele momento excepcional, todos ficaram impedidos de desembarcar e, assim, deixamos de integrar uma rede que se formava entre o Velho e o Novo Mundo.

Lamentavelmente, bem antes de 1930 e, em especial depois, este nacionalismo recebeu $\mathrm{o}$ impulso do fascismo, com que o nosso Estado autoritário 
dançou um sinistro pas de deux. Introvertíamo-nos em busca de nossas raízes, não raro sem perceber que este impulso também vinha de fora, quer como reação ao pacto colonial, quer como resultado da onda de descrédito da democracia que submergia o mundo. Muitos aqui tomavam como modelo o saneamento financeiro de Salazar em Portugal, desejando que ele fosse brasileiro. Também se admirava, primeiro, o Kaiser e, depois, Hitler, apesar de este haver instalado um populismo cruel em um país de instituições frágeis, como as nossas, que ele prontamente estilhaçou. Muitos iluminados supunham que ele não sobreviveria às eleições e seria uma espécie de personagem circense. Subestimaram-no com pensamentos carregados de desejo, deixaram-no avançar e resultou no que sabemos. É o grande risco de abrir mão das liberdades antes mesmo que seja solicitado.
O populismo é um dos nossos gostos e tentações, confundido com a democracia, e este vicejou vigorosamente no Estado Novo. A reconstitucionalização do Brasil, em 1946, restaurou a liberdade de expressão e de movimentos, entre outras. Aprofundamo-nos de fato nas reflexões sobre o processo colonial e buscamos soluções no nacionaldesenvolvimentismo.

Contudo, no quadro da guerra fria, sentimo-la aqui dentro, na carne e no sangue, com nova edição do nacionalismo e da ideia evolucionista de progresso. As contradições do regime político se agravavam quando a SBEC foi fundada, em grande parte por uma geração que havia estudado no exterior, tinha aberto as janelas mentais e havia vivido em Estados democráticos de Direito. Em grande parte, não éramos imitadores, conquanto a educação comparada fosse considerada expressão de imperialismo cultural, em 
princípio dos Estados Unidos. Paradoxalmente, o mundo não assume a fisionomia de um lago tranquilo, sem ventos e ondas. Ao contrário, pleno de contradições, as mudanças levam a efeitos indesejados e até contrárias ao esperado. Com efeito, a literatura aqui utilizada para criticar a ordem política vinha igualmente do exterior para reflexão sobre o país e sua educação: Bourdieu, Passeron, Althusser, Gramsci (aliás, com traduções duvidosas), Bowles, Gintis, Carnoy e tantos outros. Enviarnos ao exterior, portanto, também gerou contradições com as supostas intenções (ou, caso não se admita, negue-se a dialética).

Se a educação comparada é fruto do imperialismo ou se é emancipadora, se é copiativa ou base para refletir sobre nossos problemas, estabelecese uma clivagem acadêmica. Visões maniqueístas, entretanto, não têm adequado poder explicativo das suas circunstâncias. Fixam-se em luzes, que usualmente projetam sombras, ou em sombras que denotam luzes. Dificilmente captam nuanças e deixam o real escorregar, sem perceber, entre os dedos da mão.

Se há lição por mim aprendida - e expressei-a em velho artigo sobre a educação comparada foi a de um sociólogo clássico brasileiro, Alberto Guerreiro Ramos. Em pleno nacionalismo-

desenvolvimentista dos anos 1960, ele mergulhou nas dobras sutis da filosofia e da sociologia (esta última um broto relativamente recente $\mathrm{da}$ primeira). Com base na fenomenologia, traçou linhas entre o colonialismo cultural e a possibilidade de transferência científica, com adequação às realidades nacionais. Escreveu ele que uma parte da ciência elaborada transcende as sociedades que a geram e outra parte lhes é imanente. Com efeito, a ciência, no tempo e no espaço, traz as marcas das suas 
circunstâncias. A imanente pode ser fonte de reflexão e a transcendente pode tanto afastar a xenofobia quanto proporcionar o enraizamento. É preciso a arte e a ciência de distinguir uma da outra e efetuar a redução sociológica. Guarda similaridade com a distinção de cultura e civilização, tão bem traçada por Alfred Weber: a civilização transcende e é transversal às culturas, como linhas comuns, enquanto as culturas, como círculos semifechados, guardam as particularidades em que são geradas. Parece que o deputado Rui Barbosa soube antecipar esta redução nos documentos sobre a reforma educacional sequer discutida. Hoje, contudo, quase dois séculos depois da relativa Independência, acusar a colonização de estigma eterno, a explicar e justificar as falhas do país, mais parece uma relíquia arqueológica. Compreendido o passado, tenhamos certa adultez: tratemos do presente e do futuro. Participar de um mundo em globalização, exige inteligência, táticas de proteção, fixação de certos limites, para utilizá-la em nosso favor. Lutar contra ela, como se demônio fosse, é comportamento similar à quebra das máquinas na Inglaterra.

Pode parecer estranho como entrar num túnel do tempo. Por que continuamos a citar obras tão distantes e não próximas do hoje? Porque existem clássicos em que se haurem as fontes contemporâneas. Os clássicos podem até ser esquecidos, outros podem ser proscritos, outros, ainda, podem reviver. Mas que é um clássico? É uma obra cujo tempo não se acaba (ao menos por enquanto), atualizando-se e aplicando-se ao presente. Silenciosamente ou não, inspiram outras. No entanto, têm uma dificuldade: a mesma sociedade rasa $\mathrm{e}$ consumista pode valorizar a sucessão dos novos, aqueles que se situam mais perto das 
nossas linguagens e requerem menos esforço para serem decifrados. Como no fenômeno social total, as obras intelectuais se tornam produtos de validade temporal definidas, são consumíveis para ulterior descarte, assim movimentando as rodas das editoras transnacionais $\mathrm{e}$ outras. A academia e a educação correm este risco no admirável mundo novo. Por isso, é preciso coragem e capacidade para neles se inspirar. É preciso não temer que editores, pareceristas e outros considerem arcaica a sua referência. Platão e Aristóteles, por quê? Este fenômeno social total nos envolve profundamente: a ciência aparenta ser uma vitrina, periodicamente renovada, de shopping center, sempre em busca da última moda na sociedade de consumo e de espetáculo. Porém, não adianta fechar os olhos: clássicos não são consumíveis. Muito menos pessoas. Conquanto se arrisquem a ser.

Portanto, contraditoriamente, a educação comparada serve a vários propósitos. Nada é fácil: é preciso separar imanente de transcendente, com limites pouco claros, que exigem conhecimento e sabedoria. Não se pode esperar um lago liso e tranquilo e, sim, um mar encapelado.

Na educação de hoje vive-se à sombra deste fenômeno social total: diplomas são vendidos e comprados, equipamentos e materiais de ensino se impõem a qualquer custo, serviços são oferecidos e comprados, como estudo a domicílio, "clínicas de aprendizagem" e outros, ou seja, remendos de pano novo em pano velho e vice-versa. Se a oferta é em escala, custos e preços podem cair, após o frenesi da novidade. Pesquisa, como ensino, vale se for rentável e lucrativa. A moral da pós-verdade é aquela que flui, no espetáculo desenrolado à nossa vista por 
meio das redes. Não tocamos a realidade, mas criamos máscaras de disfarce, a usar conforme os papéis mais convenientes, a exemplo do teatro grego. Em tempos líquidos, tudo desliza e importa mais esquecer o antes, para valorizar o passageiro de agora.

Assim, o mundo de hoje está repleto de desafios ecológicos, sociais, econômicos, educacionais e outros. Um repto também para a educação comparada. Hoje temos testes internacionais que sacralizam rankings. Ministros caem por causa deles, como se os efeitos da educação fossem bater, valer. Afinal, é preciso sacrificar bodes expiatórios para dar satisfação pública. Pão, nem tanto. Circo, não pode faltar. É indispensável aos países se compararem uns com os outros e reduzirem evidências às suas realidades. O problema, todavia, é o rumo: os rankings se fetichizam em si mesmos, deixam de ser meios para constituírem fins. O know- how prevalece sobre o knowwhat. Podem ser amplamente utilizados para aperfeiçoar a educação, ser objetos de reflexão à luz dos diversos contextos histórico-sociais. Porém, não raro se perdem em países sem pesquisa capaz de digerir as sucessivas ondas de dados e resultados. $\mathrm{Na}$ industrialização se padronizam processos, produtos e modelos para simplificar e espremer custos. Como seria fácil se o mundo fosse como as engrenagens de um relógio analógico e se as pessoas fossem coisas. Até se pode fingir que são por algum tempo histórico. A realidade é incontrastável e prevalece apesar das sombras lançadas sobre elas.

Podia-se declarar que, entre a sociedade e a educação, existem vias de mão dupla. Evidenciam-se as mudanças recíprocas, conquanto precisemos abrir mão da linearidade pelo reconhecimento do mundo complexo onde vivemos. 
Nesse sentido, a educação comparada reflete e é refletida, muda e é mudada pelas outras ciências e pela sociedade. Pode erigir modelos inalcançáveis porque os seus pressupostos dificilmente se efetivam em todos os lugares e culturas, mas se abre também para identificar o que transcende e o que é imanente à realidade de cada um. Lembremo-nos de que os tempos, de tão cambiantes, se tornaram líquidos e, quem sabe, podem tornar-se voláteis. De que educação comparada nós precisamos para uma educação democrática de qualidade? $\mathrm{O}$ pronome é tão importante quanto o verbo: quem compõe o nós? 